\title{
Penggunaan Fungsi Pedotransfer untuk Memperkirakan Permeabilitas Tanah di Sumatera Selatan dan Riau
}

\section{Using Pedotransfer Function to Prediction of Saturated Hydraulic Conductivity at South Sumatera and Riau}

\author{
Puspita Harum Maharani ${ }^{1}$ *, Bambang Hendro Sunarminto ${ }^{2}$, dan Eko Hanudin ${ }^{2}$ \\ ${ }^{1}$ Mahasiswa Pascasarjana Jurusan Tanah, Fakultas Pertanian, Universitas Gadjah Mada \\ ${ }^{2}$ Dosen Jurusan Tanah, Fakultas Pertanian, Universitas Gadjah Mada \\ "email: puspitaharummaharani@yahoo.co.id
}

\begin{abstract}
The experiment was conducted to predict saturated hydraulic conductivity at South Sumatera and Riau from soil particles distribution, porosity and horizon median depth. Saturated hydraulic conductivity is one of soil physics properties for predicting the water movement and dissolved in the water through the soil. Most of the saturated hydraulic conductivity which analysed on laboratory was impractical, and requires a lot of cost and time. Saturated hydraulic conductivity is related to clay content, porosity adn median depth horizon. In this study 78 set of soil samples were taken from South Sumatera and Riau from May 2012 until June 2013 using permeameter. The result showed approximately success in predicting saturated conductivity from clay content, porosity median depth soil horizon $\left(R^{2}=0,675\right): \log K s=-7,245+0,077$ clay $+0,084$ porosity - 0,011 median depth horizon.

Where in this equation clay are fraction from particle size distribution, porosity are total porosity from soil structure and median depth are the middle depth of each soil horizon, and Log Ksat, saturated hydraulic conductivity expressed in $\mathrm{cm} / \mathrm{h}$. The result of regression analysis showed that clay content play more significant role with respect to Log Ks, saturated hydraulic conductivity and has been named as the effective parameter in Log Ksat calculation.
\end{abstract}

Keywords : Saturated hydraulic conductivity, clay content, porosity, median depth horizon.

\section{INTISARI}

Penelitian ini bertujuan untuk menduga nilai permeabilitas tanah dalam keadaan jenuh di Sumatera Selatan dan Riau dari tekstur tanah, porositas dan kedalaman tengah profil. Permeabilitas tanah dalam keadaan jenuh merupakan salah satu parameter sifat fisik tanah untuk memprediksi pergerakan air di dalam tanah dan zat terlarut yang berada dalam air tanah. Sebagian besar data permeabilitas tanah yang dianalisis di laboratorium dianggap tidak praktis, membutuhkan banyak waktu dan biaya. Permeabilitas tanah dalam keadaan jenuh berhubungan erat dengan kandungan fraksi lempung,porositas dan kedalaman tengah horizon. Penelitian ini dilakukan menggunakan 78 set tanah dari Palembang, Provinsi Sumatera Selatan dan Pekanbaru Provinsi Riau pada Mei 2012 sampai juni 2013 dan dianalisis di laboratorium menggunakan alat permeameter. Hasil penelitian menunjukkan mendekati keberhasilan pada pendugaan nilai permeabilitas tanah dalam keadaan jenuh dari data kandungan fraksi lempung, porositas dan kedalaman tengah horizon. Hasil yang diperoleh dari hubungan linier berganda pada data dengan $\mathrm{R} 2=0,675$. Persamaan regresi linier berganda $\log \mathrm{Ks}=-7,245+0,077$ clay + 0,084 porositas - 0,011 kedalaman tengah horizon.

Pada persamaan regresi Log Ks di dapatkan lempung merupakan fraksi penyusun tekstur tanah, porositas merupakan sifat fisika tanah yang menggambarkan struktur tanah dan kedalaman tengah pada tiap horizon tanah merupakan kedalaman horizon pada tiap lapisannya, dan permeabilitas tanah dinyatakan dalam satuan $\mathrm{cm} / \mathrm{jam}$. Hasil analisis regresi menunjukkan bahwa kandungan clay memberikan hasil yang paling signifikan terhadap permeabilitas tanah dalam keadaan jenuh dan faktor kandungan clay merupakan parameter yang paling efektif terhadap perhitungan permeabilitas tanah dalam keadaan jenuh.

Kata kunci : Permeabilitas tanah dalam keadaan jenuh, kandungan fraksi clay, porositas, kedalaman tengah profil 


\section{PENDAHULUAN}

Konduktivitas hidrolik atau yang biasa disebut sebagai permeabilitas tanah menurut Klute dan Dirksen (1986) cit Dariah et al. (2006) adalah sifat fisika tanah atau ukuran yang dapat menggambarkan kemampuan tanah dalam meloloskan air. Pergerakan air di dalam tanah merupakan hal yang penting untuk di ketahui dalam kaitannya dengan bidang pertanian. Beberapa hal yang penting dalam pergerakan air di dalam tanah diantaranya pergerakan air ke zona perakaran, keluarnya air yang berlebihan (excess water) atau disebut juga drainase, aliran permukaan (run off), dan evaporasi sangat dipengaruhi oleh kemampuan tanah dalam meloloskan air.

Permeabilitas tanah merupakan salah satu parameter fisika tanah yang penting untuk diketahui dalam mempelajari sifat hidrologis tanah. Pada saat mempelajari permeabilitas tanah tanah maka secara tidak langsung mempelajari model transportasi zat terlarut dan pengukuran aliran limpasan yang dapat digunakan untuk pendugaan erosivitas tanah. Beberapa model prediksi erosi seperti USLE, GUEST dan WEPP dan beberapa model erosi lainnya menggunakan pemeabilitas sebagai salah satu parameter pendugaan erosi. Sehingga secara tidak langsung dengan menggunakan fungsi pendotransfer dapat menentukan nilai permeabilitas tanah dalam keadaan jenuh jenuh untuk pemodelan prediksi erosi tanah.

Konduktivitas tanah dalam keadaan jenuh yang biasa disebut dengan permeabilitas jenuh merupakan salah satu sifat fisika tanah yang sangat berpengaruh terhadap kepekaan tanah terhadap erosi. Tanah yang sangat permeabel (mempunyai permeabilitas tinggi) maka tanah tersebut relatif kurang peka terhadap erosi apabila dibandingkan dengan tanah yang mempunyai permeabilitas rendah.

Fungsi pedotransfer (pedotrasnfer function) merupakan salah fungsi pendugaan secara matematis terhadap sifat-sifat fisika tanah (tekstur, struktur, dan porositas tanah) serta sifat kimia tanah (bahan organik dan atau kapur tanah) untuk menghasilkan suatu persamaan permeabilitas tanah tanah dengan menggunakan persamaan logaritma sederhana. Sudah banyak perkembangan teknologi pada penentuan permeabilitas tanah di daerah beriklim sedang, namun kendala dalam penentuan konduktivtas hidrolik secara langsung di laboratorium masih dianggap mahal (budget comsuming), menyita banyak waktu (time comsuming), dan kurangnya pemahaman terhadap pengukuran permeabilitas tanah. Pengukuran permeabilitas tanah dalam skala yang luas dianggap tidak praktis. Seringkali permeabilitas merupakan suatu parameter yang jarang diukur pada saat survei tanah dan analisis kesesuaian lahan. Keberadaan fungsi pedotransfer merupakan suatu cara menjembatani keterbatasan data yang diperoleh pada saat survei tanah sehingga dapat mendukung pada pemetaan tanah serta memperpendek rantai interpretasi pemetaan tanah dan pendugaan sifat fisika dan hidrologis tanah lainnya.

Tanah pada lokasi penelitian yang berada di daerah Subanjeriji Provinsi Sumatera Selatan dan Teso serta Lipatkain di Riau diusahakan untuk hutan tanaman industri (HTI) dengan komoditas tanaman tahunan Acacia mangium. Dalam sistem HTI Acacia dipelihara dalam jangka waktu sekitar 6 - 9 tahun, sehingga menyebabkan terjadi periode tutupan lahan yang rendah dalam sistem hutan tersebut. Penutupan lahan pada Acacia umur 6-9 tahun dapat mempunyai kemampuan menyimpan dan menahan air yang berbeda yang dipengaruhi oleh relief lahan, kedalaman lapisan pembatas serta sub group tanah. Penggunaan Acacia sebagai salah satu jenis tanaman tahunan untuk dikembangkan pada hutan tanaman industri pada satu sisi merupakan alternatif solusi bijaksana dalam dalam mengatasi masalah lahan kritis dan kebutuhan bahan baku industri belakangan ini. Selain dapat tumbuh dengan cepat, Acacia dapat tumbuh dengan baik pada lahan lahan yang kurang subur. Namun, kondisi tersebut kurang didukung dengan penyediaan perangkat pengeloaan (management tools) yang memadai.

Acosta et al. (2012) mengungkapkan penggunaan simulasi model pada fungsi pedotransfer digunakan untuk mengeksplorasi keadaan tanah, misalnya adalah efek dari praktekpraktek budidaya terhadap erosi tanah dan pengaruh irigasi tehadap hasil panen. Namun, seringkali model yang diterapkan banyak membutuhkan banyak data terkait mengenai pendugaan permeabilitas tanah dalam keadaan jenuh (Ks). Data yang dibutuhkan kebanyakan tidak tersedia dan mahal dalam pengukuran serta memakan waktu. Oleh karena itu, untuk menjembatani keterbatasan data maka digunakan fungsi pedotransfer dengan memanfaatkan informasi tanah yang sederhana dan sering tersedia untuk memprediksi sifat fisika tanah seperti nilai permeabilitas tanah. 


\section{BAHAN DAN METODE}

\section{Lokasi penelitian}

Penelitian dilaksanakan di daerah Subanjeriji Kabupaten Muara Enim Provinsi Sumatera Selatan dan di Pekanbaru, Provinsi Riau. Selanjutnya analisis tanah dilakukan di Laboratorium Fisika, Kimia dan Kesuburan Tanah Kuningan, Laboratorium Fisika Tanah Jurusan Tanah Fakultas Pertanian Universitas Gadjah Mada Yogyakarta. Penelitian ini dilaksanakan mulai bulan Maret 2012 sampai dengan April 2013.

\section{Rancangan penelitian}

Rancangan yang digunakan adalah deskriptif komparatif terhadap karakter sifat fisika dan pedologi tanah yang diambil sejumlah 6 profil tanah pada 3 lokasi yang berbeda yaitu: 3 profil yang mewakili pada plot kajian yang berada di daerah Subanjeriji Sumatera Selatan (profil GM 1, GM, 2, GM 3), 2 profil di plot kajian di Teso (Profil T 1, T 2) serta 1 profil di plot kajian di daerah Lipatkain (Profil L). Sampel tanah terusik dengan menggunakan ring sampel dan tidak terusik yang diambil dilapangan kemudian dianalisis di Laboratorium Fisika Tanah dan Laboratorium Tanah Umum Jurusan Tanah Fakultas Pertanian Universitas Gadjah Mada. Kemudian dari data hasil analisis laboratorium yang ditunjang dengan hasil analisis karakteristik profil di lapangan dibuat fungsi pedotransfer pada lokasi penelitian dengan menggunakan analisis analisis linier berganda untuk menentukan sebuah persamaan regresi permeabilitas tanah tanah.

\section{Analisis di lapangan}

Pengambilan sampel tanah terusik untuk analisis fisika tanah dan kimia tanah mengacu pada panduan pengamatan tanah dilapangan meliputi kedalaman tanah, warna tanah, tekstur tanah, struktur tanah, konsistensi tanah, pori tanah dan kondisi perakaran. Pengambilan sampel tanah terusik dilakukan dari horizon atas menuju horizon bawah dengan tujuan untuk menghindari tercampurnya horizon pada pengambilan sampel yang dapat menyebabkan kerancuan data. Sampel tanah yang tidak terusik diambil menggunakan ring sample (core) yang digunakan untuk analisis permeabilitas dalam keadaan jenuh (hydraulic conductivity) pada masing-masing horizon tanah dengan pengulangan sebanyak 3 kali yang dilakukan pada posisi tengah di setiap horizon.

\section{Analisis di laboratorium}

Analisis tanah di laboratorium meliputi analisis fisika tanah dan kimia tanah. Sifat kimia yang diamati adalah kadar bahan organik tanah dengan metode Walkley and Black, sifat fisika tanah yang diamati adalah: kadar lengas tanah, kemantapan agregat tanah, kemantapan agregat tanah, shear strength, permeabilitas tanah, berat volume dan berat jenis tanah serta tekstur tanah.

Tabel 1. Jenis dan metode analisis sifat fisika dan kimia tanah

\begin{tabular}{cccc}
\hline No. & Parameter & Satuan & Metode \\
\hline 1 & C-organik & $\%$ & Walkey and Black \\
2 & Tekstur tanah & $\%$ & Metode pipet \\
3 & BV dan BJ & $\mathrm{g} / \mathrm{cm}^{3}$ & Gravimetri \\
4 & Kemantapan agregat & $\%$ & Ayakan basah kering \\
5 & Permeabilitas tanah & $\mathrm{cm} / \mathrm{jam}$ & Ring sampel \\
6 & Shear strenght & Joule & Tekanan \\
\hline
\end{tabular}

Sumber: Pusat Penelitian Tanah Bogor (1983) cit. Hardjowigeno (2003)

\section{Analisis data}

Analisa data sifat fisika tanah dan kimia yang didukung dengan data karakteristik profil pada plot kajian diolah dan dianalis secara deskriptif komparatif untuk mendapatkan data hasil penelitian yang digunakan dalam mendapatkan fungsi pedotransfer untuk menyusun pemodelan permeabilitas tanah. Selanjutnya data di lapangan di analisis di laboratorium untuk mendapatkan data penunjang. Metode yang digunakan pada pengembangan fungsi pedotransfer untuk memperkirakan permeabilitas tanah adalah dengan menggunakan metode metode linier berganda (regresi multivarian) non parametrik yang diolah menggunakan software SPSS 20 dengan menggunakan prediktor utama berupa berat volume tanah, tekstur tanah (\% pasir, $\%$ debu dan \% klei), kadar bahan organik dan geometric mean diameter (GMD) dan menggunakan semua data tambahan yang diperoleh selama analisis di laboratorium. Selanjutnya Wosten et al. (2001) berpendapat 
selain analisis regresi, teknik-teknik baru seperti Artificial Neural network (ANN), dan klasifikasi dan regresi pohon semakin sering digunakan untuk pengembangan fungsi pedotransfer. Perkembangan aktual fungsi pedotransfer ditunjukkan dengan menggambarkan sebuah studi kasus. Evaluasi praktis pada fungsi pedotransfer terbukti menjadi alat yang baik untuk menilai akurasi yang diinginkan dari fungsi pedotransfer untuk aplikasi tertentu.

\section{HASIL DAN PEMBAHASAN}

\section{Deskripsi profil tanah}

Lokasi penelitian berada di daerah Subanjeriji Provinsi Sumatera Selatan dan di daerah Teso serta Lipat Kain diusahakan untuk budidaya Hutan Tanaman Industri (HTI) dengan komoditas Acacia mangium sebagai bahan baku pulp dan kertas. Ordo tanah pada lokasi penelitian di Sumatera Selatan di blok Subanjeriji pada tapak penelitian Gemawang 1, Gemawang 2 dan Gemawang 3 masuk dalam ordo Ultisol. Pada lokasi penelitian yang berada di Provinsi Riau berada di daerah Kampar dan dibagi menjadi 3 tapak yang berbeda yaitu Tesso 1, Tesso 2 dan Lipat Kain. Tanah pada ketiga tapak penelitian diklasifikasikan dalam ordo tanah Inceptisol.

Analisis deskripsi profil tanah untuk mengembangkan fungsi pedotransfer didukung oleh pernyataan Calhoun et al. (2001) bahwa deskripsi morfologi tanah dan deskripsi lapangan telah dimanfaatkan dalam pengembangan fungsi pedotransfer. Selanjutnya dalam penelitian McKenzie dan Jacquier (1997) menyimpulkan bahwa tambahan deskriptor morfologi dalam survey diperlukan untuk meningkatkan kapasitas prediksi sifat-sifat tanah. Pada beberapa keadaan sebagian fungsi pedotransfer dikembangkan di bawah kondisi tanah yang tidak mempunyai sifat dan perlakuan khusus seperti kandungan bahan organik yang tinggi, konsentrasi garam yang tinggi, dan kompaksi atau pemadatan.

\section{Korelasi antar sifat fisika tanah}

Hasil analisis korelasi antar sifat fisika tanah (Tabel 2) menunjukkan bahwa beberapa sifat fisika tanah yaitu berat volum (BV), shear strength (SS), MWD basah dan kandungan clay cenderung menurunkan nilai sifat fisika tanah yang lain, sedangkan berat jenis tanah (BJ), bahan organikl (BO), permeabilitas (Ks), kandungan sand dan silt, porositas serta MWD kering cenderung menaikkan nilai sifat fisika tanah lainnya. Hubungan antara antar parameter sifat fisika tanah menunjukkan bahwa antara kandungan bahan organik (BO) dengan kedalaman tengah horizon tanah saling berhubungan dan bersifat signifikan dengan angka koefisien korelasi sebesar -0,722 pada level kepercayaan 99\%. Hubungan kandungan $\mathrm{BO}$ dan kedalaman tengah horizon sangat erat. Semakin dalam suatu horizon tanah makan akan semakin menurun kandungan bahan organik dalam tanah.

Matrik korelasi sifat fisik tanah terhadap
permeabilitas tanah dalam keadaan jenuh $(\mathrm{Ks})$

Matrik korelasi antar sifat fisika tanah dengan permeabilitas tanah dalam keadaan jenuh (Ks) (Tabel 3) menunjukkan bahwa beberapa sifat fisika tanah yaitu kedalaman tengah horizon, shear strength (SS), kandungan silt, dan MWD basah cenderung menurunkan laju permeabilitas tanah dalam keadaan jenuh (Ks), sedangkan kandungan $\mathrm{BO}$, clay dan porositas cenderung mengurangi laju permeabilitas tanah dalam keadaan jenuh (Ks). Hubungan antara kandungan clay dan Ks saling berhubungan dan bersifat signifikan. Hubungan antara kandungan clay dan Ks sangat erat dengan koefisien korelasi 0,664 pada level kepercayaan 99\%. Semakin tinggi kandungan clay maka akan semakin tinggi laju Ks. Menurrut Minasny dan Hartemink (2011) dikemukakan bahwa semua fungsi pedotransfer menggunakan kandungan pasir, debu, lempung dan bahan organik sebagai prediktor. 
Tabel 2. Hasil analisis korelasi antar sifat tanah

\begin{tabular}{|c|c|c|c|c|c|c|c|c|c|c|c|c|}
\hline Parameter & $\begin{array}{l}\text { Kedalaman } \\
\text { Tengah } \\
\text { Horizon }\end{array}$ & $\mathrm{BV}$ & BJ & $\mathrm{BO}$ & SS & Log Ks & Sand & Silt & Clay & Porositas & $\begin{array}{l}\text { MWD } \\
\text { Kering }\end{array}$ & $\begin{array}{l}\text { MWD } \\
\text { Basah }\end{array}$ \\
\hline $\begin{array}{l}\text { Kedalaman } \\
\text { Tengah } \\
\text { Horizon } \\
\end{array}$ & 1,000 & $0,545^{* *}$ & $0,308^{* *}$ & $-0,722^{* *}$ & 0,095 & $-0,351^{* *}$ & $-0,109$ & $-0,092$ & $-0,005$ & $-0,272^{*}$ & $-0,627^{* *}$ & 0,114 \\
\hline $\mathrm{BV}$ & $0,545^{* *}$ & 1,000 & $0,274^{*}$ & $-0,517^{* *}$ & 0,130 & $-0,153$ & $-0,240^{*}$ & $-0,115$ & 0,191 & $-0,712^{* *}$ & $-0,355^{* *}$ & 0,137 \\
\hline $\mathrm{BJ}$ & $0,308^{* * *}$ & $0,274^{*}$ & 1,000 & $-0,477^{* *}$ & $-0,122$ & 0,191 & 0,025 & 0,090 & $-0,087$ & $0,473^{* *}$ & $-0,214$ & $-0,256^{*}$ \\
\hline SS & 0,095 & 0,130 & $-0,122$ & $-0,101$ & 1,000 & $-0,426^{* *}$ & $-0,065$ & $0,402^{* *}$ & $-0,374^{* *}$ & $-0,183$ & $0,231^{*}$ & $0,730^{* *}$ \\
\hline Log Ks & $-0,351^{* *}$ & $-0,153$ & 0,191 & $0,246^{*}$ & $-0,426^{* *}$ & 1,000 & 0,011 & $-0,417^{* *}$ & $0,664^{* *}$ & $0,248^{*}$ & 0,046 & $-0,642^{* *}$ \\
\hline Sand & $-0,109$ & $-0,240^{*}$ & 0,025 & 0,215 & $-0,065$ & 0,011 & 1,000 & 0,042 & $-0,110$ & $0,242^{*}$ & 0,082 & $-0,027$ \\
\hline Silt & $-0,092$ & $-0,115$ & 0,090 & 0,076 & $0,402^{* *}$ & $-0,417^{* *}$ & 0,042 & 1,000 & $-0,664^{* *}$ & 0,192 & $0,356^{* *}$ & $0,490^{* *}$ \\
\hline Clay & $-0,005$ & 0,191 & $-0,087$ & 0,098 & $-0,374^{* *}$ & $0,664^{* *}$ & $-0,110$ & $-0,664^{* *}$ & 1,000 & $-0,264^{*}$ & $-0,203$ & $-0,548^{* *}$ \\
\hline
\end{tabular}

Keterangan: **. Correlation is significant at the 0.01 level (2-tailed).

*. Correlation is significant at the 0.05 level (2-tailed).

MWD = Mean weight diameter

Tabel 3. Matrik korelasi sifat fisik tanah terhadap permeabilitas tanah dalam keadaan jenuh (Ks)

\begin{tabular}{ccc}
\hline Variabel & Log Ks & Keterangan \\
\hline Kedalaman Tengah Profil & $-0,351^{* * *}$ & $\mathrm{~b}$ \\
Bahan Organik & $0,246^{*}$ & $\mathrm{~b}$ \\
SS & Variabel & $\mathrm{b}$ \\
Silt & $-0,417^{* *}$ & $\mathrm{~b}$ \\
Clay & $0,664^{* *}$ & $\mathrm{~b}$ \\
Porositas & $0,248^{*}$ & $\mathrm{~b}$ \\
MWD Basah & $-0,642^{* *}$ & $\mathrm{~b}$ \\
\hline
\end{tabular}

Hasil analisis regresi linier berganda terhadap faktor-faktor sifat fisika tanah yang mempengaruhi permeabilitas tanah dalam keadaan jenuh

Berdasarkan hasil analisis linier berganda faktor-faktor yang mempengaruhi permeabilitas tanah dalam keadaan jenuh (Ks) (Tabel 4) menggunakan metode stepwise. Variable yang muncul pada analisis regresi linier berganda metode stepwise merupakan seluruh faktor yang diduga berpengaruh nyata (signifikansi 5\%) terhadap permeabilitas tanah dalam keadaan jenuh. Variabel yang diduga berpengaruh terhadap Ks adalah kandungan clay, porositas dan kedalaman tengah horizon tanah. Menurut McKenzie dan Cresswell (2002) selama penelitian dan survei tanah, untuk pengukuran permeabilitas tanah dalam keadaan jenuh (Ks), fungsi deskripsi morfologi tanah menambahkan pengukuran stabilitas agregat, berat volume, porositas dan estimasi langsung kelas ukuran partikel (\% sand, $\%$ silt dan \% clay) dan yang paling tepat bagi sifat morfologi secara konvensional adalah derajat struktur, ketebalan horizon dan tipe horizon. Pengulangan pengukuran dari permeabilitas tanah bertanggung jawab pada setiap tipe horizon fungsi dari tiap variabel dari horizon tanah yang sangat berperan dalam penentuan permeabilitas tanah adalah.

Nilai $R$ square berdasarkan tabel diperoleh nilai 0,687 . Nilai $R$ square merupakan kriteria ketepatan suatu fungsi regresi. Nilai $R$ square berkisar antara 0-1 dimana semakin mendekati angka 1 maka model fungsi regresi semakin tepat dan menghasilkan nilai koefisien regresi yang nyata $\left(R^{2}>0,5\right)$. Lebih lanjut Agus dan Suganda (2006) mengungkapkan bahwa permeabilitas tanah dapat dipengaruhi oleh tekstur dan struktur tanah. Pada tanah yang didominasi oleh tekstur pasiran akan mempunyai permeabilitas tanah yang tinggi, 
sedangkan pada tanah yang mempunyai tekstur lempung maka akan mempunyai permeabilitas tanah yang kecil, namun apabila tanah bertekstur lempung mempunyai agregasi butir tunggal yang mantap maka akan mempunyai permeabilitas tanah yang tinggi.

Nilai adjusted $\mathrm{R}$ square dalam hasil analisis regresi diperoleh nilai sebesar 0,675 sehingga dapat disimpulkan bahwa sebesar $67,5 \%$ faktor yang mempengaruhi Ks dapat dijelaskan oleh variabel kandungan clay, porositas dan kedalaman tengah horizon tanah, sedangkan sisanya sebesar $32,5 \%$ dijelaskan oleh variabel lain diluar model regresi yaitu faktor BV, BJ, bahan organik, shear stregth, sand, silt, MWD basah dan MWD kering. Nilai $\mathrm{R}$ square dari hasil regresi menunjukkan hasil yang tidak begitu tinggi karena sifat permeabilitas tanah merupakan sifat fisika tanah yang mempunyai variasi yang sangat tinggi di lapangan. Didukung oleh pendapat dari Timlin et al. (2004) berpendapat bahwa permeabilitas tanah dalam keadaan jenuh sulit diperoleh karena sangat sensitif terhadap kondisi tanah, seperti pemadatan, pori makro, ukuran partikel, suhu, dan udara terperangkap, dan dengan demikian sangat bervariasi.

Tabel 4. Hasil analisis linier berganda terhadap faktor-faktor sifat fisika tanah yang mempengaruhi permeabilitas tanah dalam keadaan jenuh (Ks)

\begin{tabular}{lcccc}
\hline \multicolumn{1}{c}{ Variabel } & Koefisien Regresi & t hitung & Signifikansi & Keterangan \\
\hline Clay & 0,077 & 11,297 & 0,000 & $*$ \\
Porositas & 0,084 & 5,458 & 0,000 & $*$ \\
Kedalaman tengah horizon & $-0,011$ & $-3,578$ & 0,001 & $*$ \\
\hline Konstanta & $-7,245$ & & & \\
$R$ & 0,829 & & & \\
$R$ square & 0,687 & & & \\
Adjusted $R$ square & 0,675 & & & \\
F hitung & 54,246 & & & \\
\hline
\end{tabular}

Menurut Minasny et al. (2002) fungsi pedotransfer secara sederhana adalah mengubah satu variabel menjadi variabel yang lain dari data yang tersedia menjadi sebuah model pendugaan yang dibutuhkan. Selanjutnya Minasny et al. (2002) berpendapat variabel yang dibutuhkan yang sulit diperoleh dan mahal untuk di dapatkan adalah data prediksi sifat hidrolik tanah dan karakteristik pasokan hara. Berdasarkan Tabel hasil analisis regresi linier berganda faktor-faktor yang mempengaruhi permeabilitas tanah dalam keadaan jenuh (Ks) (Tabel 4) menghasilkan persamaan regresi $\log \mathrm{Ks}=-7,245+0,077$ clay $+0,084$ porositas - 0,011 kedalaman tengah horizon.

Selanjutnya Pachepsky dan Rawls (1999) cit. Nemes dan Rawls (2004) berpendapat bahwa distribusi ukuran partikel digunakan pada hampir semua fungsi pedotransfer. Distribusi ukuran partikel menjadi pasir, debu dan clay merupakan pendekatan paling umum dalam penentuan fungsi pedotransfer.

\section{KESIMPULAN}

1. Deskripsi profil tanah yang berada di lokasi penelitian di daerah Subanjeriji Sumatera Selatan dideskripsikan ke dalam ordo Ultisol dan lokasi penelitian di daerah Teso dan Lipat
Kain di Riau di deskripsikan ke dalam ordo tanah Inceptisol.

2. Berdasarkan hasil analisis regresi linier berganda terhadap lokasi penelitian menunjukkan bahwa faktor independen sifat fisika tanah yang paling mempengaruhi Ks adalah kandungan clay, porositas dan kedalaman tengah horizon.

3. Nilai $R$ square paling tinggi dari model pendugaan Ks (Model 1) diperoleh nilai 0,675 dengan persamaan regresi $\log \mathrm{Ks}=-7,245+$ 0,077 clay $+0,084$ porositas $-0,011$ kedalaman tengah horizon.

\section{DAFTAR PUSTAKA}

Acosta, C.A., Lascano, R.j., Stroosnijder, L. 2012. Test of the Rosetta Pedotransfer Function for Saturated Hydraulic Conductivity. Journal of Soil Science, 2012, 2, 203-212. Published SCRIP. USA

Agus, F dan Suganda, H. 2006. Penetapan Konduktivitas Hidrolik Tanah dalam Keadaan Jenuh: Metode Lapang dalam Sifat Fisik Tanah dan Metode Analisisnya. Balai Besar Litbang Sumberdaya Lahan Pertanian. Departemen Pertanian. 
Calhoun, F.G., Smeck, N.E., Slater, B.L., Bigham, J.M., dan Hall, G.F., 2001. Predicting bulk density of Ohio soils from morphology, genetic principles, and laboratory characterization data. Soil Science Society of America Journal. 65, 811-819.

Dariah, Ai., Yusrizal, dan Mazwar. 2006. Sifat Fisika Tanah dan Metode Analisisnya. Balai Besar Litbang Sumberdaya Lahan Pertanian. Bogor

Hardjowigeno, S. 1993. Klasifikasi Tanah dan Pedogenesis. Akademika Ressindo. Jakarta.

Minasny, B dan Hartemink, A.E. 2011. Predicting Soil Properties in the Tropics. Earth-Science Reviews $106 \quad$ (2011) 52-62. Elseiver.Australia.

Minasny, B., McBratney AB., McKenzie NJ., Grundy MJ. 2002. Predicting Soil Properties Using Pedotransfer Functions and Environmental Correlation in. Guidelines for surveying soil and land resources: 349-367. Australia.
McKenzie, N.J. and Cresswell, HP,. 2002. Estimating Soil Physical Properties Using More Readlily Available Data. CSIRO Publishing. Australia.

Nemes, A. and Rawls, W.J. 2004. Soil Texture and Particle-Size Distribution as Input to Estimate Soil Hydraulic Properties. Development in Soil Science Volume 30: 47-70. Elsiever. USA.

Timlin, D.J., Williams, R.D., Ahuja., dan Heathman G.C. 2004. Simple Parametric Methods to Estimate Soil Water Retentio and Hydraulic Conductivity. Development in Soil Science Volume 30: 47-70. Elsiever. USA.

Wostern, J.H.M., Pachepsky, Ya.A. dan Rawls, W.J. 2001. Pedotransfer Functions: Bridging the Gap Between Available Basic Soil Data and Missing Soil Hydraulic Characteristics. Journal of Hydrology 251 (2001): 123-150. Elsiever Science. USA. 